\title{
Graduate Student Support: Using Wellness Programming to Promote Con- nection, Community, and Sense of Belonging
}

Beth A. Bucher MSW, Ohio State University, Electrical and Computer Engineering Graduate Program

Beth Bucher, MSW, Graduate Program Coordinator, Electrical and Computer Engineering, College of Engineering, The Ohio State University. 


\title{
Graduate student support: Using wellness \\ programming to promote connection, \\ community and sense of belonging
}

\begin{abstract}
Community and a sense of belonging are commonly accepted as two of the biggest predictors of academic success in higher education. Additionally, student distress, accidental death from risky behavior, and suicide can be combatted primarily through connections, according to the University's Suicide Prevention Program. Due to the nature of the work, it is easy for graduate students to become isolated and disconnected. Increased rigor, perfectionistic tendencies and demand for original impactful contributions make graduate school stressful. The very nature of the learning process creates dissonance by presenting hurdles and problems to be solved. Creating connection, community and a sense of professional belonging can make our graduate programs thrive instead of ridden with student attrition, students just making it through, or worse.
\end{abstract}

Initiatives were begun in a large graduate engineering program. This is a discussion of the good, the bad, and the ugly of the first attempts of the programming. Some of the components include small group leadership of new students, Get Launched for Success Workshop Series, weekly email outreach spotlighting University resources, suicide risk assessment, Group Wellness Coaching, collaboration with graduate student organization officers, student interest surveys, and "Surviving the Holidays" workshop presented by campus counseling services.

Support was solidified from faculty leadership to create a wellness culture. The department chair was approached for approval of a budget for food for events in autumn semester. Faculty who had experienced a student's accidental death just months prior were approached about recommending their advisees participate in Group Wellness Coaching with the objective of creating community and connection.

In order to be intentional, consultation regarding objectives, outcomes and evaluation was sought. University resources utilized include Counseling \& Consultation Services, Office of Diversity, Student Wellness Center, Engineering Career Services, University Center for the Advancement of Teaching, and Center for the Study of Student Life. It is the author's hope that presenting the material will encourage other staff and faculty to collaborate across their campuses to create holistic graduate student programming to meet unmet needs in their areas.

\section{Background}

Creating a wellness culture, connection, community, and professional sense of belonging are vital elements to all graduate students from the most well-adjusted and engaged to the most disenfranchised and fragile. Sense of belonging includes fit in the academic discipline, being respected and valued by peers, in the research group, by the faculty, and program representatives. Wellness initiatives not only lead to more engaged and productive students, the initiatives are associated with increased retention and completion rates (Okahana, H., Allum, J., Felder, P.P., \& Tull, R.G. 2016). Creating a thriving culture also enhances recruitment and increases enrollment. 
Mind, body, and spirit are integral to both health and well-being. The World Health Organization (WHO) defines health as physical, mental and social well-being. Well-being is a continuum ranging from illness and crisis to high-level engagement and happiness. All components interact and affect the others. Excess focus on one pursuit (such as research or courses) without some balance can cause lower quality of the work and interfere with other areas. For example, a student may neglect exercise or relationships but focus intensely on academics. Academic performance can suffer if the student gets sick or becomes isolated. The degree of emotional connection, "mattering", or sense of professional belonging is significantly related to wellness levels (Myers \& Sweeney, 2008).

There are many stressors throughout the academic cycle.

"...students frequently question their identity, relationships, direction and worth during transition to school which produces turmoil and crisis. Stress of relocation, separation from family and friends, new people, academic challenges, discrepancy between expectations and reality, loneliness, and lack of support all significantly relate to attrition" (Lee, D., Olson, E. A., Locke, B. Michelson S. T. \& Odes E, 2009, p. 5).

Students past the initial transition face stressors related to making progress in research or projects, successfully completing academic milestones, and job hunting. Even the most resilient students can be negatively impacted by these stressors. In the worst case scenario, high risk behavior or intentional suicide attempts may result.

Graduate faculty, staff and administrators need to be aware that graduate students experience high rates of depression, anxiety (nervousness, stress, loneliness), and distress. Distressed individuals coping with stressors can lead to high risk behaviors or worse. Suicide is the second leading cause of death for college students. Groups at elevated risk include (1) male, (2) older (graduate and professional), (3) international, and (4) returning veterans. Being a graduate student puts a person at risk. For international students, males, or returning veterans, the risk is compounded. Protective factors include a caring culture, strong connections to others, and a culture that supports help-seeking (Granello, 2016).

Dr. Okahana (et al., 2016) released recommendations to increase retention and completion rates for underrepresented domestic minorities (URM). The completion rates in STEM for URM were so close to all domestic students (54\% versus $55 \%$ respectively), this author proposes that the recommendations apply to every graduate student. Not only are the recommendations applicable to retention and completion rates, the recommended support services will also build the protective factors that reduce high risk behavior mentioned above. The findings of the study follow.

Due to high turnover of leadership in student-led organizations, institutional mechanisms are the best investments. Development of a suite of formal support services to address academic, motivational, and holistic competencies is the ideal strategy. Evidence was found to "suggest that doctoral students were more affected by their program's climate than their advisor and faculty support" (Okahana et.al, 2016, p. 6). In early and later stages of degree completion, students rely on peer supports, mentorships, and personal determination (Okahana, et.al, 2016). 
Research has shown that one person cannot provide all the support needed. Student expectations and needs vary. In a guide for new students, Dr. Lunsford and Dr. Baker (2016) offer a selfassessment for students to identify their individual expectations and needs. It is recommended new students seek out and develop a network of mentoring relationships "An academic faculty advisor may also be a mentor but that is not always the case nor does it have to be" (Lunsford, L.G., et al., 2016. p. 2).

\section{Models of Mentoring}

Peer mentorship can take many forms from structured to more fluid and social. There are several models nationally. At the University of California-Merced, mentors and mentees are connected through a monthly speaker series and free catered lunch. Participants are given an interest survey at the beginning of the semester. Based on the results, monthly speakers are invited to give a 15 minute presentation and lead a 45 minute round table discussion. (UCMerced, Graduate Peer Mentor Program, 2016). The Graduate School at Washington University in St. Louis funds peer mentoring. Off campus venues like museums and sporting events are suggested activities. Professional workshops and etiquette workshops are additionally suggested (Graduate Student Peer Mentoring Handbook, n.d.). The Purdue University Graduate School pairs mentors and mentees. Participation is expected during weekly discussions over meals between pairs, and during large group monthly dinner meetings hosted for all participants. There are ten weekly topics assigned for mentors to discuss one on one with mentees. (eMentoring Expectations, 2017). The University of California, Riverside Graduate Division, facilitates first-year mentees connecting with one to three other new students and a peer mentor in a related field. These are called families. Two to three families form "teams" with a faculty mentor. Two to three teams then form groups. Some type of meeting is encouraged weekly. Groups meet at least once a quarter. (GradSuccess. Mentorship Program, 2017)

\section{Professional Development}

Professional development is another part of academic success. Initiatives should give students the opportunity to develop non-technical skills like communication, teamwork, and leadership skills. In addition to individual contributions, graduates need to be team players in the current global market, whether in academia or industry. Good communication skills are required especially for successful leadership. These include oral, written, cross-cultural and presentation skills. Students need to be able to explain work in layman's terms to participate in interdisciplinary teams. Universities can embed this in courses and supplement with experiences outside of class (Itani, M., Srour, I., 2015). Career planning should also be provided in professional development.

\section{Pilot Year: Suite of Support Programing}

\section{Peer Mentoring: "Leadership Opportunity"}

Current MS students were asked to volunteer to meet with a small group of new MS students to answer questions, offer advice, and share contact information. The active students developed 
leadership skills and added to their resumes by volunteering. The new students were given access to experience community building and sense of belonging.

A few volunteers were recruited through a "call for leaders". The rest were recommended by faculty. Eighteen current students led small groups of four to five people. There were a total of about 80 new MS students. The leaders were coached online with conversation starter ideas and a one page flyer of communication tools. The flyer covered open/closed ended questions, active listening description, and the importance of body language. Leaders completed a one page profile with a picture, a short self-introduction, and advice to incoming students. The profiles were sent to the corresponding group members prior to the event. The day of the event, a printed list of campus resources along with the assigned group members were given to leaders. The event was held the day after the program's graduate orientation over a lunch hour. Food was provided. Academic projects and research dominated the conversations.

Feedback was obtained from an informal survey distributed by email to participants and leaders asking if they knew anyone before the event, what was discussed, what they would suggest be done differently, and if contact would be maintained throughout the year. Positive responses were received from new and current students. Several of the current students sought out faculty and staff to express their wish for this opportunity as a new student. Next year there are plans to continue the effort, expand leaders to at least two per group to more fully answer questions, and to include PhD students.

Professional Development: Get Launched for Success: 2 part MS workshop in collaboration with the Student Wellness Center and Engineering Career Services

The goal of the series was to develop strength awareness and to apply and articulate the awareness to academic team projects and in the job hunt (on resumes, in cover letters, and interviewing). The hope was to assist students conceptualize and identify their unique contributions. In conversation with students during the workshop, the strengths material seemed too vague or too short to be fully processed. Some students left the first workshop early and half did not return for the second workshop.

In three previous years, Engineering Career Services led workshops for MS students that covered job hunt topics. Separate workshops covered resume specifics, interviewing skills and job hunt tools. Between 40 and 50 students attended the workshops which filled the room used for the event. The events finished with many questions from participants often running past the scheduled times. This is a stark contrast to the low participation with the new format. In following years, there will be a return to the traditional career services workshops.

\section{Suicide Screening: $R U O K$ ?}

This is a program administered by University Suicide Prevention office. The program screens for risk of suicide. Students participate voluntarily. Emails are sent to graduate students in the program from the Chair expressing concern for stresses and well-being. A link is included in the email. If a student chooses to participate, the link takes that person to an anonymous survey. A RUOK? Administrator, who is also a licensed counselor, monitors the surveys and recommends 
resources based on the identified concern. The student is sent an email notification that a message is waiting. The student then logs in to view the message. If there are a total of three dialogues or correspondences, there is a $90 \%$ chance that the student will use the recommended resources. This is the second year of participation.

Possible scoring on the survey follows includes Very Highest Risk, High Risk, Moderate Risk, or Minimal Risk. The survey results follow for October 2016. Out of 457 students, there was an overall response rate of $3.5 \%$ or a total of sixteen students. Eight percent is the national response rate average. Unfortunately, three of the sixteen scored at the Very Highest Risk. Five scored at High Risk. Eight scored at Moderate Risk. Three students dialogued after the initial counselor response went out. There were a total of three dialogues with one student which increases the chance of service utilization to ninety percent.

\section{Peer Connection: Collaboration with a graduate student-led organization}

The department assisted with organization, marketing, cost-sharing, and creating an online student interest survey for a student-hosted donut social. The event was held simultaneously at two locations, main campus and a research center on west campus. There were only about twelve students that attended. However, there was a good response rate to the online student interest survey. Out of about 460 students, there was over seventeen percent response rate or 77 students that participated. Seventy-five percent (or 57 students) indicated interest in job hunt topics. Seventy percent (or 53 students) indicated interest in information about local events, attractions, and venues. Sixty-two percent (or 48 students) indicated interest in social events like laser tag, bowling, etc. Fifty-nine percent (or 44 students) indicated interest in technical writing. Fiftyeight percent (or 45 students) indicated interest in communication skills. Fifty-seven percent (or 43 indicated) interested in living healthy \& balanced life.

\section{University Resources: A bi-weekly email outreach}

Emails were sent to the MS students for eight weeks highlighting one campus resource per message. A list was included at the end of each email of all discussed resources. The Center for the Study of Student Life (CSSL) had assisted Freshman Exploration with development of this kind of messaging. It served as a template but was edited for a graduate student audience. At the completion of the eight weeks, CSSL invited ECE MS students to take a survey. The department provided three $\$ 25$ gift cards to be awarded randomly to survey participants. Approximately ten percent of the 224 MS students replied.

The responses indicated the following. Ninety percent agreed or strongly agreed that it was convenient to learn about resources this way. Eighty-nine percent agreed or strongly agreed that the emails make them feel like the engineering program is helping them to achieve academic goals. Eighty-five percent agreed or strongly agreed that knowing resources helps them to feel connected to the University. Eighty-three percent agreed or strongly agreed that the emails were informative. Seventy-seven percent clicked links to resources. Seventy-four percent want to receive the emails in the future. Seventy percent agreed or strongly agreed that using resources makes them feel more confident in achieving academic goals. Sixty-six percent would like to 
learn more about the resources by visiting Engineering staff or advisors. Forty-eight percent report that they would like to find out more by visiting outside of the program.

\section{Group Wellness Coaching: Cohesion, Connection, Community Building, and Self-Care}

Connection, sense of belonging, community building, and self-care are the goals of Group Wellness Coaching. A group of faculty advisors whose students all work in a computer lab together, supported recommending their $\mathrm{PhD}$ advisees attend. This lab includes five faculty advisors with 25 students. The Wellness Coaching Coordinator from the Student Wellness Center facilitates the sessions in early spring. Lab mates form small groups of four to six people. Students self-identify personal goals. Simple questions are used to assist groups in discussing strategies for meeting goals.

\section{Conclusion}

Future initiatives include further development of holistic programming that addresses professional development and student interest survey results. Refinement will be done for distributing campus resource information and calendar of program events.

An online optional unit or web page may be created to address professional development with live events to supplement the online resources. Leadership development would be part of the unit or web page including understanding personality types, workstyles, motivation, and attitude. Career-life balance or wellness will be addressed. Communication skills will also addressed including presentation skills and one on one discussion with others outside of the research field. Students need to be able to articulate their contributions in layman's terms and how those contributions impact a larger picture. "Speed interviewing" is scheduled for the upcoming year in which program coordinators and academic advisors will meet with students to for mock interviews.

Connection between new students and current students will be further developed to place the groups in teams. PhD student will be included. Team leaders will be coached in person as well as online to strengthen their leadership skills and experience. Teams will meet at three scheduled brown bag events in autumn and a welcome back lunch in early spring. Topics and round table discussion are organized for these gatherings.

Joshua Love, President of Kinema Fitness wrote in Forbes Magazine (Sept. 13, 2013), “A successful program takes time and constantly evolves so it can be integrated in the fabric..." of the culture. Wellness programming is a complex and long-term commitment requiring institutional leadership and support. 


\section{References:}

American College Health Association-National College Health Assessment (ACHA-NCHA-II) Institutional Data Report. (Spring 2014) (http://www.acha.org/)

Council of Graduate Schools. Chapter 5 Promising practices: Mentoring and advising. PhD Completion Project. 2008. Retrieved from http://www.phdcompletion.org/promising/mentoring.asp

eMentoring Expectations. Purdue University Graduate School (n.d.). (Retrieved January 29, 2017 from https://www.purdue.edu/gradschool/ementoring/expectations.html )

Garcia-Williams, A. G., Moffitt, L., Kaslow, N. J. (2014). Mental health and Suicidal Behavior Among Graduate Students. Academic Psychiatry, 38: 554. DOI:10.007/s40596-014$0041 \mathrm{y}$

Graduate Assembly Graduate Student Happiness \& Well-Being Report (2014) University of California, Berkley http://ga.berkeley.edu/wp content/uploads/2015/04/wellbeingreport_2014.pdf

Graduate Peer Mentor Program (Grad PMP). (n.d.). University of California, Merced. (Retrieved July 13, 2016 from http://gradlife.ucmerced.edu/Grad_PMP)

Graduate Student Peer Mentoring Handbook (n.d.). Macrander, A. (Ed). Washington University in St. Louis Graduate School. (Retrieved July, 2016 from http://graduateschool.wustl.edu/files/graduate/Peer_Mentoring_Handbook.pdf )

Graham, M. J., Frederick, J., Byars-Winston, A., Hunter, A.B, Handelsman, J. (2013). Increasing Persistence of College Students in STEM. Science Volume 341, Issue 6153:1455$6 \cdot$ September 2013. DOI: 10.1126/science. 1240487

Granello, D. H. (2016) Campus Suicide Prevention REACH Training Program, [PowerPoint Slides].

Itani, M., Srour, I. (2015). Engineering Students' Perceptions of Soft skills, Industry Expectations, and Career Aspirations. Journal of Professional Issues in Engineering Education and Practice. DOI:10.1061/(ASCE)EI.1943-5541.0000247.

Lee, D., Olson, E. A., Locke, B. Michelson S. T. \& Odes E (June 2009). The Effects of College Counseling Services on Academic Performance and Retention. Journal of College Student Development, Volume 50, Number 3, pp. 305-319. https://muse.jhu.edu/article/265820/pdf

Longfield, A., Romas, J., \& Irwin, J. D. (2006). The Self-Worth, Physical and Social Activities of Graduate Students: A Qualitative Study. College Student Journal, Volume 40, Number 2, pp. 282-292. 
Love, J. (September 12, 2013). Five Reasons Corporate Wellness Is More Important Than Ever. Forbes Magazine, Retrieved December 2016 from http://www.forbes.com/sites/theyec/2013/09/12/five-reasons-corporate-wellness-is-moreimportant-than-ever/\#4d3b153077af

Lunsford, L.G., Baker, V. L. (2016). Great Mentoring in Graduate School: A quick Start Guide for Protégés. Council of Graduate Schools, Occasional Paper Series, Number 4. http://cgsnet.org/ckfinder/userfiles/files/CGS_OPS_Mentoring2016.pdf

Mentorship Program (n.d.). University of California, Riverside. Graduate Division, GradSuccess. (Retrieved January 29, 2017 from http://gradmentors.ucr.edu/ )

Myers, J. E. \& Sweeney, T. J. (2008). Best Practices Wellness Coaching: The Evidence Base for Practice American Counseling Association, Journal of College Counseling \& Development, Volume 86. https://ryan-reese.squarespace.com/s/Myers-Sweeney-2008-Wellness-Counseling.pdf

Okahana, H., Allum, J., Felder, P.P., \& Tull, R.G. (2016). Implications for practice and research from Doctoral Initiative on Minority Attrition and Completion (CGS Data Sources PLUS \#16-01). Washington, DC: Council of Graduate Schools. http://cgsnet.org/sites/default/files/2016.03\%231601\%20Discussion\%20on\%20DIMAC.pdf 